\title{
Chinese energy and climate policies after Durban: Save the Kyoto Protocol
}

\author{
Yu Hu, Carlos Rodríguez Monroy
}

\begin{abstract}
A B S T R A C T
Nowadays, one of the urgent issues regarding global climate change is to discuss the future of the second period of the Kyoto Protocol. However, the divergence of views and opinions among parties in the last Conference of the Parties of the United Nations Framework Convention on Climate Change, held in Durban in December 2011, is still large. One of the bones of contention is whether the emerging developing countries, like China, should make commitments and legally bind themselves to a Green House Gas (GHG) reduction target in near future. As the largest GHG emitting country, China and its energy and climate policies will play an important role in global climate change and will also significantly influence the other countries' policies and the global climate negotiation. In this paper, we review the current differences among parties in the Durban Conference, and we analyze the recent situation, barriers, and future policies in China. Finally we highlight the impact and potential effect of Clean Development Mechanisms in avoiding China's barriers regarding climate change. Results show that China is making a great effort to mitigate climate change by establishing and reforming its energy and climate policies in order to achieve a low-carbon development. At the same time, more innovation and international collaboration is needed in China to achieve this goal.
\end{abstract}

\section{Contents}

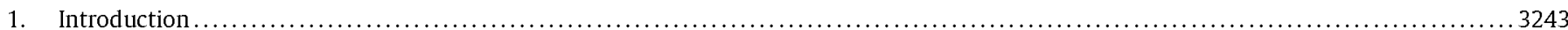

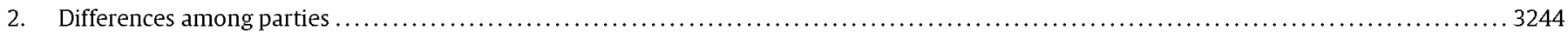

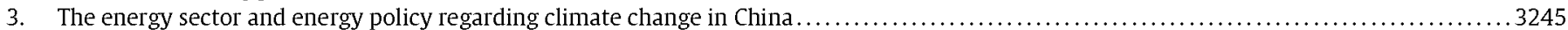

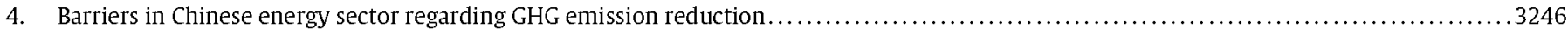

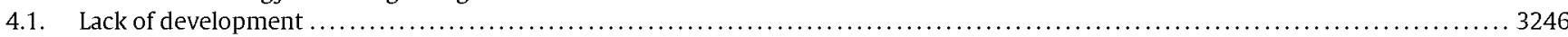

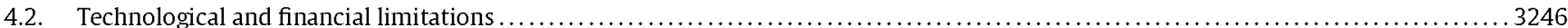

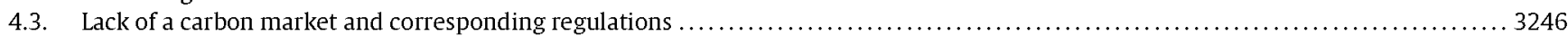

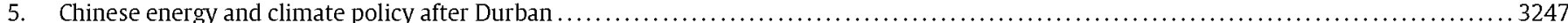

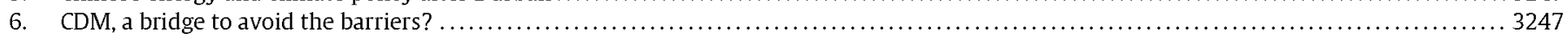

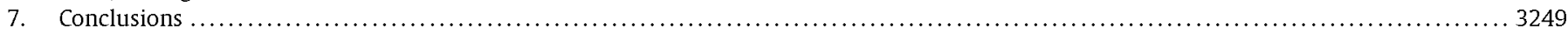

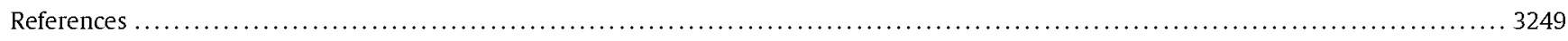

\section{Introduction}

To deal with the rising problem regarding climate change, the United Nations issued the United Nations Framework Convention on Climate Change (UNFCCC) in 1992 [1], which is considered to be the first international climate treaty. The UNFCCC became legally effective in 1994. Three years later in 1997, the Kyoto
Protocol [2] was adopted on December 11, 1997 in Kyoto, Japan, and entered into force on February 16, 2005. Under the Kyoto Protocol, industrialized countries (Annex I countries) agreed and committed to reduce the collective greenhouse gas (GHG) emissions by $5.2 \%$ from the 1990 level. The first period of the Kyoto Protocol is from 2008 to 2012, and the corresponding GHG emission reduction commitments by the Annex I countries expire at the end of 2012. Because of this reason, it becomes urgent to discuss and set a new global regulation about reduction of GHG emission between different parties in a second period of the Kyoto Protocol. However, currently the divergence of views and opinions among nations and parties is still largely shown in the international conference and 
the negotiation process about the second commitment period of the Kyoto Protocol is still not successful. In 2009, the 15th Conference of the Parties (COP15) of the UNFCCC was held at Copenhagen, Denmark. The Copenhagen Accord [3] was approved in the conference and the parties decided to postpone the negotiation about legally binding commitment and extension of the Kyoto Protocol to later conferences in Cancun, México, in Durban, South Africa, and in Qatar. In 2011 the 17th Conference of the Parties (COP17), was held in Durban, where different issues were discussed, such as the Green Climate Fund [4] and a new Roadmap [5] for GHG reduction after 2020. The key issue, the future of the Kyoto Protocol, remains unclear since no further detailed commitment was made. After the meeting, Canada has formally withdrawn from the Kyoto Protocol. This was considered to be a large setback of global climate cooperation. Recent analysis report by the Instituto Español de Estudios Estratégicos (IEEE) [6] states that the result of Durban Conference was a compromised result that could be accepted by the EU, China and the US, and it also intends to set up a legally binding scheme fighting climate change to deal with the problems of energy security and food security.

One of the bones of contention in the Durban Conference is whether the emerging developing countries should make commitments and legally bind themselves to a GHG reduction target in the second period of the Kyoto Protocol. Without doubt, China, as the largest developing country and the largest GHG emitting country, stood in the center of this controversy. China and its energy and climate policies will play an important role in global climate change and will also significantly influence the other countries' policies and the global climate negotiation. In this paper, we review the current differences among parties in the Durban Conference, and we analyze the recent situation and barriers in the Chinese energy sector regarding GHG emission reduction. Additionally, we analyze the Chinese energy and climate policies based on the current information. Finally, we highlight the impact and potential effect of Clean Development Mechanisms (CDM) in avoiding China's barriers regarding $G H G$ reduction.

\section{Differences among parties}

Although a package of agreements and compromise was achieved in Durban, it is a clear fact that serious differences exist among the parties. The main perspective contradiction is mainly between the developed countries and the emerging developing countries such as China, India, Brazil, and South Africa.

Some developed countries reached a consensus that they refuse to extend their commitment in the second period of the Kyoto Protocol unless other countries, or at least the main developing countries, accept binding GHG emission reduction obligations equally. Due to the rapid economic growth GHG emissions produced by emerging developing countries are taking more and more a significant part of the total global emissions. However, developing countries claim that developed countries should be responsible for the largest share of historical and current global GHG emissions and are not willing to accept a commitment to reduce their own GHG emissions. They argue that among other issues they still need to fight poverty which affects a high percentage of the population.

As the second largest GHG emitting country, the US supports the "road map" plan proposed by the European Union (EU). However, it shows a negative attitude towards the negotiation about legally binding carbon emissions and the global climate fund at the Durban Conference. Japan, Canada, and Russia, also oppose the second commitment period of the Kyoto Protocol. Studies show that "If these three countries abandon the Kyoto Protocol, the GHG emissions of the countries that are still obliged to observe the Kyoto emissions targets will account for only about $16 \%$ of the total", and that the "Kyoto Protocol will further lose its effectiveness" [7]. Russia [8] proposes to redefine the standards under the Kyoto Protocol to re-distinguish between developing and developed countries, and revise this distinction periodically. Canada formally abandoned the Kyoto Protocol after the Durban Conference and was blamed by many countries and NGOs.

The EU proposes the EU "road map" plan, and emphasizes that a "legally binding emission reduction framework" among the major GHG emitting countries, including industrialized countries and also emerging developing countries, must be issued before 2018. The EU claims that the second commitment period of the Kyoto Protocol should be aligned with the road map. In their proposal, a new regime following the Kyoto Protocol framework should be established by 2015 and finally enter into force by the year of 2020 [5]. This proposal was also supported by many other parties like the Alliance of Small Islands States (AOSIS) and the Least Developed Countries (LDC). They claim that even though they have been making great effort on GHG reduction under the Kyoto Protocol, EU's GHG emissions accounts for only $11 \%$ of global emissions. Without the participation the remaining countries and an international framework and global cooperation, the problem of global warming cannot be possibly resolved [5].

In contrast, both China and India are emphasizing that their GHG emission are mainly because of their developing process and their huge population. Moreover, they argue that developed countries should achieve the commitment on the first period of the Kyoto Protocol, especially to reach the target of GHG reduction and provide financial and technical support to developing countries [9]. China declared that it has achieved its energy intensity reduction target for the "Eleventh Five-Year Plan" (2006-2010), and is also adopting a positive attitude and various actions currently to deal with the climate change problem. Furthermore, China has set a target of reducing energy intensity by $17 \%$ during the "Twelfth Five-Year Plan" period from 2011 to 2015 [10]. China stated that all these actions and targets have been approved and legalized by its National People's Congress. Regarding the issue of legally binding GHG emission reduction obligations, China proposed five conditions for joining a legally binding global climate change treaty after 2020 [11]. Firstly, the Kyoto Protocol and its second commitment period must be confirmed and legally binding. Secondly, the Green Climate Fund must be established. Thirdly, the mechanism agreed in the former conferences in the areas of technology transfer, reforestation, transparency, and capability building should be established. Fourthly, the situation of developed countries fulfilling their commitments during the first period of the Kyoto Protocol must be evaluated. Lastly, the principle of "common but differentiated responsibilities" must be adopted. China claimed that it would take the responsibilities and obligations corresponding to its level of economic development.

The outcome, because of the differences among parties, of the Durban Conference was considered to be not very significant. However, the agreements achieved regarding the second period of the Kyoto Protocol were criticized by many NGOs as unclear, and not specific. There is no applicable evaluation and sanction mechanism in place. The Green Climate Fund is still in the paperwork stage, there is still a long process ahead and many negotiations are needed, such as the source and the administrative scheme, to finally set the fund into practice.

Due to its large economic dimension and impact on climate change, the changes in Chinese energy and climate policy will be one with the highest impact in the global negotiation. China was blamed for the fact that its current energy intensity reduction target in the current Five-Year Plan was only a relative target, since there was no limitation on the absolute value of GHG emission. In the Durban Conference, China has shown a positive attitude in changing its policy to adapt to the new climate situation. And China also offers 

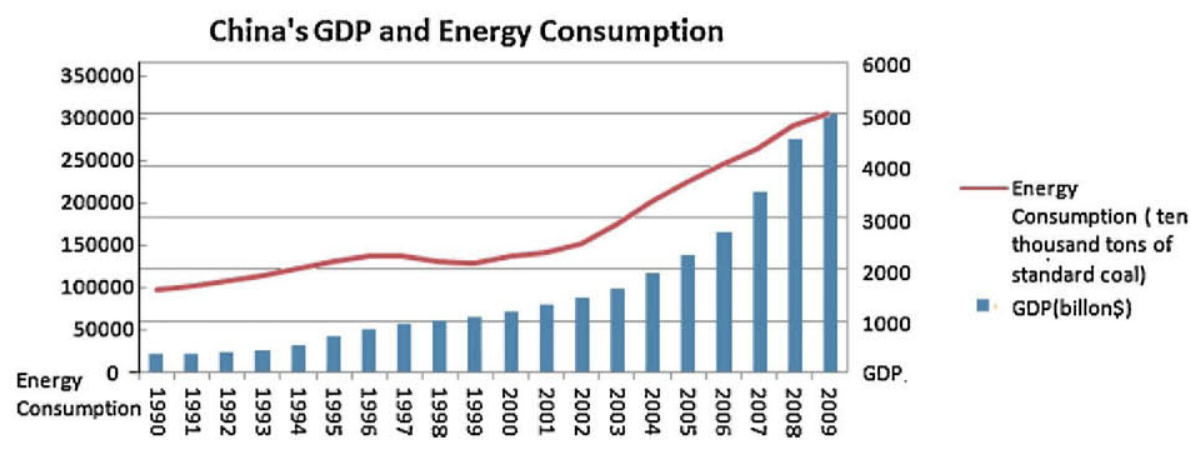

Fig. 1. China's GDP and energy consumption 1990-2009.

Source: World Bank and National Bureau of Statistics of China

the possibility for a legally binding GHG reduction target in the next global regime after 2020. Many voices state that now it is the right time for the developed countries, especially Japan, Canada, Russia and the United States to show their good disposition. "Within the European Union, which has spearheaded efforts in 2011 to maintain momentum in the Kyoto process, officials maintain that China has been helpful and cooperative" [12]. Since China has now the largest and GHG emission rate in the world, it is inevitable that China control the absolute GHG emission in the long run. The pressure comes not only from international negotiations but also from China's own sustainable development. A realistic scenario could be that China commits to mitigate its GHG emission in the near future, and join a new legally binding global GHG reduction scheme between 2018 and 2020.

\section{The energy sector and energy policy regarding climate change in China}

The remarkable growth experienced in China since the Chinese economic reform in 1978 led by Deng has been discussed intensively among economists and policy-makers all over the world. With an average annual real GDP growth rate of $10.4 \%$ in the period 1990-2009 according to World Bank data, China has experienced one of the fastest growths ever seen, and the term "Chinese miracle" is widely spread to refer to this incomparable phenomenon. In parallel, the growth in energy consumption has also been remarkable. In the year 2010, the energy consumption has been more than 3 billon tons of standard coal, as shown in Fig. 1, which is three times more than the amount in the year 1990. The average annual energy consumption growth rate in this period is $6.26 \%$ (data source: National Bureau of Statistics of China). Since 1990, the electricity and heat generation sector grew the most, representing $48 \%$ of Chinese CO2 emissions in 2009 [13].

The energy consumption is predicted to be continuously growing at a high rate because of the development and industrialization in China, and the huge and uncertain energy demand is one of the most important challenges for environmental and sustainable development in China in the near future [14]. Among the various energy resources, coal is the main one in the Chinese energy supply structure. In the year of 2009, according to the National Bureau of Statistics of China, coal provides $77.3 \%$ of the total energy consumption in China, followed by oil (9.9\%), natural gas (4.1\%) and other energies which include hydro power, nuclear power and wind power (8.7\%). Currently, coal is filling a large share of the growing energy demand in China, "where energy-intensive industrial production is growing rapidly and large coal reserves exist where there are only limited reserves of other energy sources" [13]. The high percentage of energy from coal in the total energy consumption has caused substantial environmental problems [15]. At the same time research shows that energy efficiency in China still needs to be improved when compared to that of industrialized countries $[16,17]$.

As indicated and as a consequence of the large energy consumption, China is the largest GHG emitting country in the world according to the World Bank. The $\mathrm{CO}_{2}$ emission of China in the year 2008 is 7031 million tons, considerably larger than the US (5461 million tons). The recent IEA report shows that from a global point of view, two-thirds of global emissions for 2009 originated from just ten countries, and the two leading countries, China and the United States produced $12.0 \mathrm{Gtons} \mathrm{CO}_{2}$ and $41 \%$ of world $\mathrm{CO}_{2}$ emissions [13]. At the same time, the report also notes that China generates $24 \%$ of world $\mathrm{CO}_{2}$ emissions with $20 \%$ of the world population, while the US contributes with over $18 \%$ of world $\mathrm{CO}_{2}$ emissions with less than $5 \%$ of the global population [13].

The Chinese government has started to take into account sustainable development in the energy policy since last century. In 1994, the Chinese government published its first white paper regarding sustainable development, "China's Agenda 21 - White Paper on China's Population, Environment, and Development in the 21st Century" [18]. Later in 2003 China issued the "Program of Action for Sustainable Development in China in the Early 21st Century" [19]. In these documents, China has not stated a clear and quantitative goal about GHG reduction. Three years later, in 2006 China issued the "Eleventh Five-Year Plan", in which GHG emission reduction was a concern for the first time in its Energy Plan. In June 2007, China issued the "National Action Plan on Climate Change", as a national working plan on the issue of climate change. Different measures and goals were proposed in the "Eleventh Five-Year Plan (2006-2010)" and the "National Action Plan on Climate Change".

In the energy sector Chinese government set a goal of "more or less $20 \%$ " energy intensity reduction and optimization of the energy consuming structure. Different research projects $[16,17,20]$ have analyzed the policies and programs carried out by China to support these targets. The results show that energy intensity target for the year 2010 may be roughly achieved (the energy intensity reduction is $19.1 \%$ according to "China's Policies and Actions for Addressing Climate Change (2011)") and the actions taken by China have significantly reduced the growth of GHG emissions and will possibly reduce the absolute quantity in the future. However, the energy structure optimizing targets are failing. Liu et al. [21] reviewed the policies and applications taken by China to achieve a low-carbon economy, and as a result stated that China will benefit from the lowcarbon policy in its sustainable development. The research work also suggests that more efforts are needed for the Chinese policy makers to revise the current policies, promote structural change, and pay more attention to economic and market mechanism innovation.

According to the research work which reviewed the energy policies since 1953 by Yuan and Zuo [22], "A clear increasing level of 
attention of Chinese government" to the aspects regarding climate change has been found from a historical point of view, more concern has been shown in the area of energy efficiency, pollution reduction, renewable energy, and GHG emission. It was found that GHG emission reduction first appeared in the Eleventh Five-Year Plan (2006-2010) with only a general statement. Then in the Twelfth Five-Year Plan (2011-2015), detailed targets and objectives with various measures are stated in a dedicated chapter discussing this issue. These results show that in China there is a continuous energy policy concern about climate change. China has roughly achieved its goal in the past five years, and there are reasons to believe that the country is on the right way to make further achievements on GHG emission control. On the other hand, China is still facing difficulties in adopting legally binding emission caps in the near future.

\section{Barriers in Chinese energy sector regarding GHG emission reduction}

According to the current situation of the energy sector in China different barriers can be found in China that prevent it from reducing its GHG emission and surpassing the emission caps. The key barriers which affect the Chinese GHG emission policies include the lack of development, the limitation of technology and finance, and the lack of regulation and functionality of a financial system in the carbon market. These issues will be analyzed sequentially in the following sections.

\subsection{Lack of development}

China is the fastest growing developing country in the world and its energy demand is also increasing at a very fast rate, as shown in Fig. 1. According to Ma et al. [23] the industrial sector represents the largest share of energy consumption in China (more than $71 \%$ ), followed by the residential (10\%) and transportation (7\%) sectors in the year 2007. The energy consumption structure clearly shows that China is still experiencing the industrialization and urbanization process. This trend is forecasted to continue for a relative long time period [24,25], and a "large GNP loss could take place" if China adopted a legally binding GHG reduction target [26].

In Durban, the Chinese Delegation restated that there is a huge gap between the GHG emission reduction and the growing energy demand in China. Thus, China must "explore a new development system with lower carbon emissions". More specifically, China must build on "industry structure and consumption patterns with lower carbon emissions" [10]. In order to achieve the "low-carbon development" and fulfill the emission reduction commitments, China had decided to slow down its economic growth and reduce its energy consumption intensity during the "twelfth-five year plan" (2011-2015) [27]. The GDP growth target was set at 7\%, as well as to control the annual energy consumption below 4.1 billion tons of standard coal. China has also planned to reduce its GHG emissions per unit of GDP in the year 2020 at a rate of $40-45 \%$ based on the 2005 levels [10]. However, the fast rate of development makes it difficult to achieve this target. A recent research by Zhang et al. [28] claims that the living standard of Chinese people has been increasing during the year 1990-2007, and the economic scale will be the main impact factor on China's GHG emission in the future. Besides, an increase of the total amount of GHG emissions could be observed, but with a decreasing emission per capita rate due to the development process in the near future. Based on the large potential for economic development in China, it can be predicted that the increase in the amount of GHG emissions is going to last a relative long time.

\subsection{Technological and financial limitations}

As discussed in the previous section, China's energy structure has mainly relied on coal which has provided about $77 \%$ of the total energy consumption in 2009. Lin [29] states that the rapid economic development requires a huge amount of low priced energy resources. Because of its availability and relative low price, coal is the first choice for many developing countries. On the other hand, the consumption of coal releases the largest amount of GHG when compared to other energy resources for providing the same amount of energy [29]. Besides the dependency in coal resources, energy efficiency in China still needs to be improved, according to the Annual Report on China's Low-Carbon Economic Development 2011 [30]. Currently the total efficiency rate for coal utilization in China is only about one half that of industrialized countries. This fact shows that the "technology level of clean coal utilization in China is far behind", and more R\&D and international technology cooperation is required to achieve the clean energy targets [30].

Research work shows that China has abundant renewable energy resources [30]. Various renewable energy systems could be applied in China to provide alternative energy sources other than traditional energy based on fossil fuels, but the technologies have not been widely adopted due to the high investment cost and the current technical barriers, especially in the new technologies such as concentrated solar thermal energy, and smart grid systems [31-33]. At present, less than $8 \%$ of the energy consumption is provided by renewable energy and nuclear energy. Meanwhile, Judith [34] claims that the quality of Chinese domestic technology is still under development and it forces energy developers to import costly generating units overseas, thus inhibiting the growth of the local industry, while international manufacturers are now willing to invest in China in a large economic scale [34].

\subsection{Lack of a carbon market and corresponding regulations}

Nowadays, market-based environmental policies have begun to be applied in a number of countries, and tradable permit programs are playing an important role in the global climate scheme [35]. The emissions trading market systems are already operating around the world [36]. Among these markets, the European Union Allowances (EUAs) market has become the most important market and accounted for $84 \%$ of the global carbon market value in 2010 [37]. The carbon market is strongly dependent on policy and regulations, which comprise both international and national policy, such as the Kyoto Protocol commitment and the national cap on emissions for industries [38]. Research shows that the equilibrium price of Certified Emission Reductions (CER) is determined by demand and supply in the international CDM market, which represents the aggregate demand and aggregate supply of GHG emission rights in the world [39].

China is the largest CER providing country in the world in the carbon trading scheme of Clean Development Mechanisms (CDM). However, there is no influential domestic carbon market in China, and there are no specialized carbon trading policy and regulations guiding market activities. Yuan [40] states that the "Lack of coordination between market mechanism and government command-and-control" is one of the major barrier for China to reduce its $\mathrm{GHG}$ emissions. Chinese $\mathrm{GHG}$ reduction projects and the corresponding trading activities need to be exercised on the international market. The consequence of lacking domestic market and regulatory framework is losing pricing power in the market. If China finally adopts a new world GHG reduction scheme and legally binding GHG emission caps, the domestic demand and supply parties will be greatly affected. Thus, an advanced carbon trading system and the corresponding policy and regulations are needed in China 


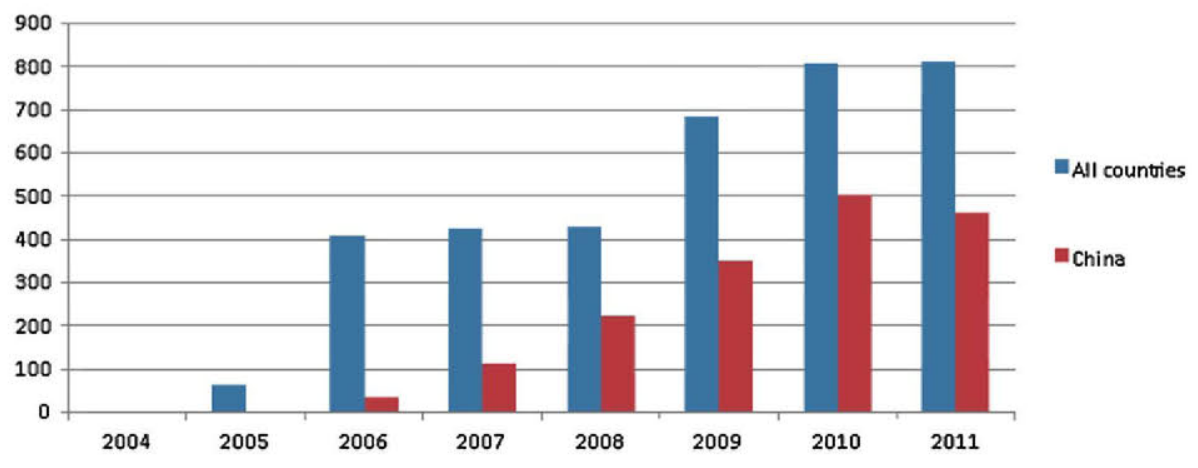

Fig. 2. Annual number of registered CDM projects in the period 2004-2010.

to control the risk and market volatility taking into account China's actual social and economic conditions.

\section{Chinese energy and climate policy after Durban}

In the Durban Conference which took place in December 2011, China stated its future GHG reduction plan for the next few years. The delegation from China informed that the Chinese government had decided to reduce significantly the GHG emission in the coming years using various methods. By the year 2015, a reduction of $17 \%$ GHG emissions should be achieved based on the 2010 levels. To achieve this target a detailed policy regarding the GHG emission reduction in the "Twelfth Five-Year Plan (2011-2015)" was established [10].

In November 2011, China published the document "China's Policies and Actions for Addressing Climate Change" [41], which covered different aspects in the area of energy and climate change. Two work plans, the "Comprehensive Work Plan for Energy Conservation and Emission Reduction during the 12th Five-Year Plan Period" (2011) and the "Work Plan for Greenhouse Gas Emission Control during the 12th Five-Year Plan Period (2011-2015)" were released to make an overall arrangement for energy conservation, emission reduction and GHG emission control for the next 5 years [41].

According to the "China's Policies and Actions for Addressing Climate Change" [41], in the regulatory aspects, China will strengthen its legal system building and strategic planning. Special laws in addressing climate change will be studied and enacted, especially in the area of renewable energy [14]. Existing relevant laws, regulations, rules and standards will be reviewed taking into account the aspects of climate change [41]. China will reform its policies to intensify statistical and research work on renewable resources, resources supply and consumption and GHG emissions monitoring.

In order to increase the productivity of the resources and reduce the environmental impact, China is planning to upgrade its economic structure. In the next five-year plan (2016-2020), China will promote industrial upgrading and optimization, accelerate the transformation of the economic development pattern and develop a circular economy. The changes in the development pattern are expected to limit the expansion of energy-hungry and high-emission industries. China will also speed up the development of modern services and new emerging industries with strategies of significance [41].

In the energy sector, China will rationally control its total energy consumption, formulate energy development plans, and define the total consumption control target and the mechanism to share the tasks and responsibilities among industries and sectors [41]. At the same time China is continuing to implement key energyconservation projects, optimizing energy mix and developing clean energy. Technologies with high energy efficiency will be promoted, such as energy-saving technologies, and renewable energy technologies. China will put more effort on developing renewable water, wind, solar, geothermal and biomass energy in accordance with local conditions [41]. The investment in renewable energy is expected to continue to increase in the coming years, and according to Bloomberg, by 2014 China will become the largest single market for renewable energy with an annual expenditure of just under $\$ 50 \mathrm{bn}$, accounting for $21 \%$ of the world market [42].

To control carbon emissions, China will steadily launch lowcarbon pilot projects and organize provinces, autonomous regions and municipalities to undertake those pilot projects to compile low-carbon development plans and actively explore low-carbon development modes with local characteristics. On the other hand, China will develop carbon sink projects such as the key shelterbelt construction project in Northwest, Northeast and North China and along the Yangtze River, as well as projects to return farmland to forest, and natural forest conservation projects, among others [41].

Besides the aspects mentioned above, China will establish a new carbon emissions trading market as well as reforming the regulations and policies regarding carbon trading in order to standardize the trading action in the market and finally optimizing the allocation of resources, and realize the objective of controlling GHG emissions at a minimum cost with the help of a effective market system $[41,43]$.

\section{CDM, a bridge to avoid the barriers?}

The Clean Development Mechanisms (CDM) is a flexible mechanism developed under the Kyoto Protocol, as specified Article 12. The objective of CDMs is to help the developing countries (Non-Annex I parties) to achieve sustainable development. The CDM allows industrialized countries to "invest in emission reduction projects wherever it is cheapest globally" [44]. Considered as a financial tool, CDMs create a commercial value based on the additional reduction of GHG emissions. The availability of carbon trading can provide additional revenue sources and investment sources for financing a project [45]. Technology transfers are also promoted by CDM by transferring climate friendly technologies to developing countries such as renewable energy technologies and energy efficiency improving technologies [46].

Up to the end of 2011 (data updated on December 8, 2011), China is one of the most successful countries that take advantage of CDMs. According to UNFCCC statistics, $46.57 \%$ of the registered activities (1690 projects in total) and a surprising $63.94 \%$ of the expected average annual CERs from registered projects are from China, as shown in Figs. 2 and 3. Among the 1690 registered projects hosted by China, more than $80 \%$ are renewable energy projects. These projects are expected to generate 181 million CERs which represent about half of the total expected average annual CERs. The average expected CERs generated by a renewable energy project 


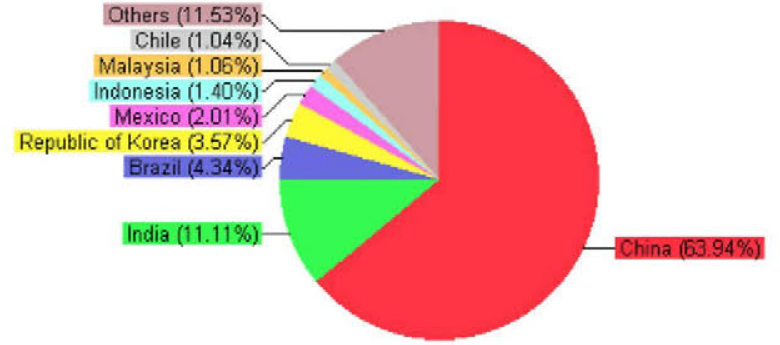

Fig. 3. Expected average annual CERs from registered projects by host party.

is 132,430 . From a geographical distribution point of view within China, the Yunnan province hosts more registered projects (184) than any other province, followed by Inner Mongolia (176), Sichuan
(153), Gansu (117). In total 13 provinces host more than 50 registered projects as shown in Fig. 4. It is also worth noting that the geographical distribution of the registered projects is significantly correlated with the geographical distribution of current and potential hydropower and wind power in China.

According to different researchers, CDMs are an indispensable incentive to promote renewable energy because of the additional finance from carbon trading [24,45]. Moreover, CDMs could be a helpful aspect in energy development, especially in the areas with higher GHG emissions and lower GDP per capita [47]. However, the technology transfer promoted by CDM is not significant in China. In 2010 less than $10 \%$ of the projects are with known technology transfer [46], as shown in Fig. 5. Research work also shows that there is a pressing need for the Chinese government to amend its current interim CDM regulations [48].

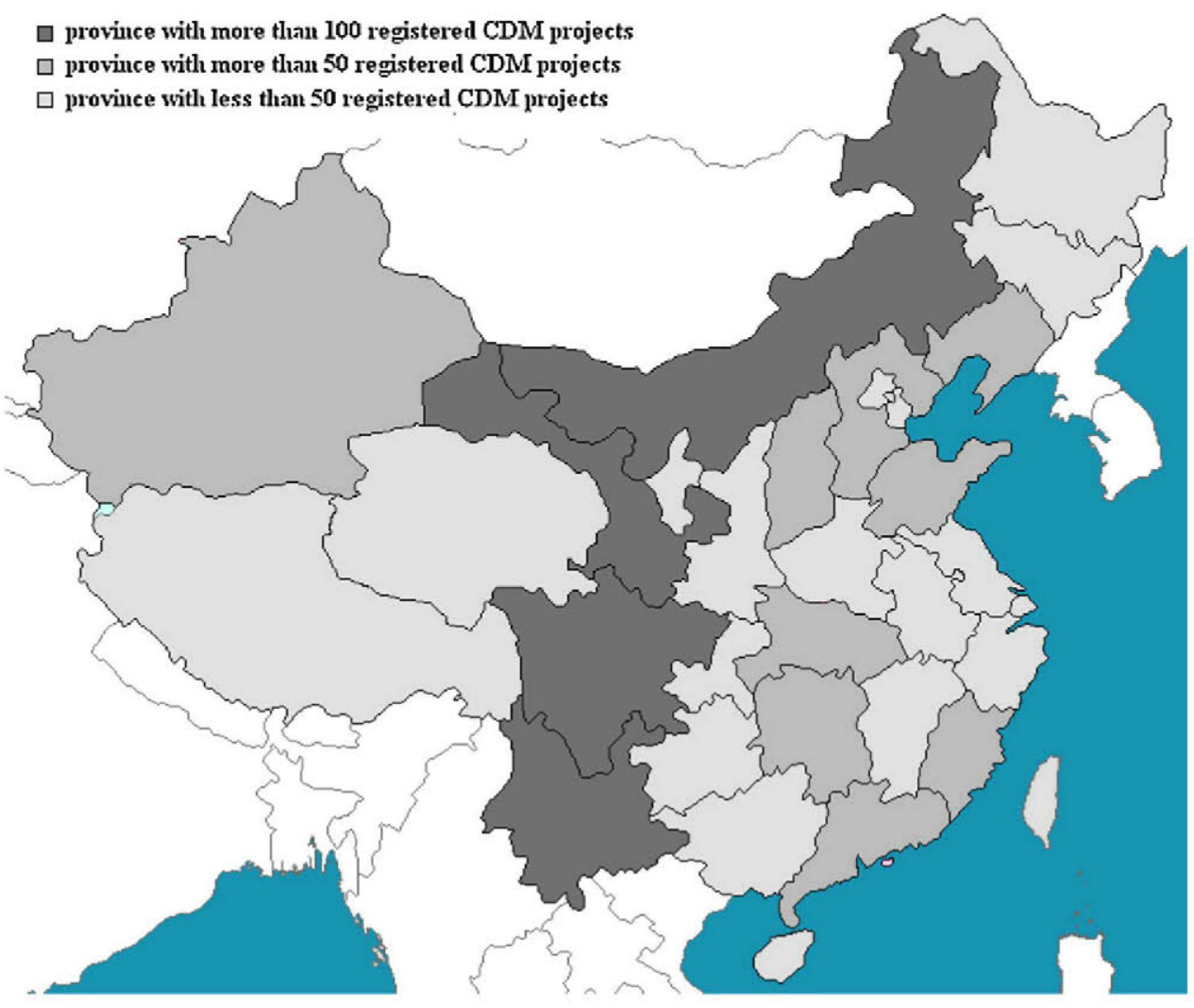

Fig. 4. Geographic distribution of registered CDM project in China.

Trends in technology transfer claims by host country

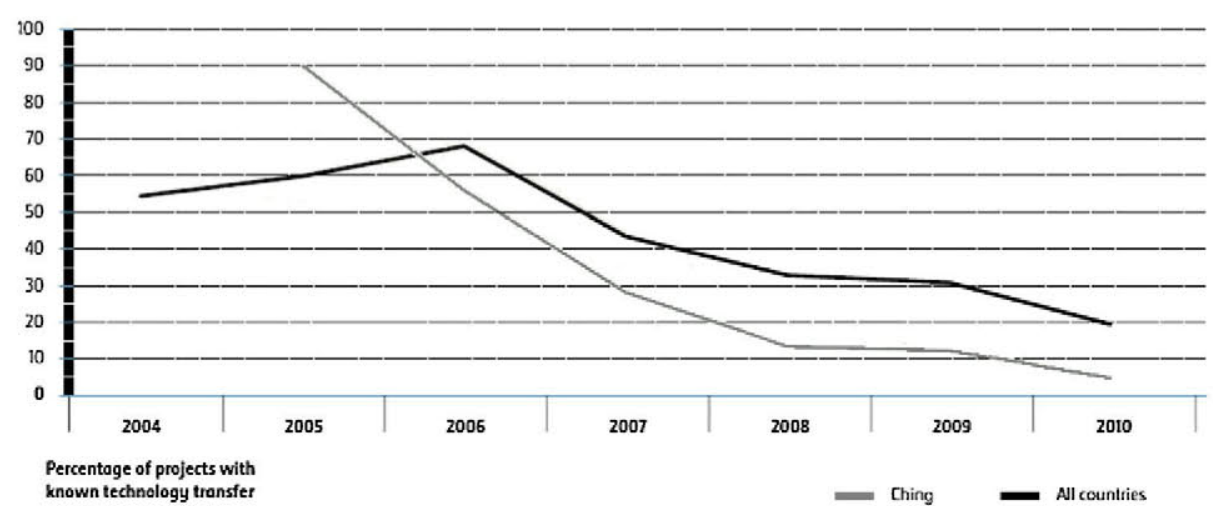

Fig. 5. Trends in technology transfer claims by host country. 
As suggested by many researchers [21,49], the barrier between increased energy demand and GHG emission reduction can be mitigated through the application of renewable energy technology with the help of CDMs. Considering the large potential of renewable energy resources in China, the increasing and uncertain fossil energy price, and the Chinese Government's efforts to promote renewable energy using new policies, the renewable energy sector will have more competitive advantages with regard to the traditional fossil energy. Another important problem is the low level in technology development regarding renewable energy and energy efficiency. R\&D companies and technology companies could be more active in Chinese GHG reduction by developing environmentally friendly technologies. On the other hand, technology transfer originated in developed countries should be more promoted in the CDM scheme, as suggested by Charikleia Karakosta in the recent research work [50], and the government should promote technology development and transfer by reforming the policy and regulatory system. At the same time, the government should also do more work in establishing a carbon trading market as well as its corresponding policy and regulations. As a financial innovation, the carbon market could be attractive for investment for different sectors, bringing more global collaboration to cover the development and technology barriers and generating profits by GHG reduction.

\section{Conclusions}

Currently one of the most urgent issues regarding global climate change is to decide the future of the Kyoto Protocol, of which the first period of commitment expires at the end of 2012. So far, no clear agreement has been reached among parties. One of the most important disputes among parties in the negotiation to save the Kyoto Protocol is whether to include emerging developing countries in a legally binding emission cap. More detailed negotiations are needed to be conducted according to the principle of "common but differentiated responsibilities", which emphasizes the responsibilities of industrialized countries. Considering the fact that GHG emissions from emerging developing countries are rising significantly and show a growing percentage of the global GHG emissions, the trend to control the GHG emission from these countries is inevitable in the long run. Based on the negotiations in Durban, a realistic scenario could be that China commits itself to mitigate its GHG emission in the near future, and join a new legally binding global GHG reduction scheme around 2018-2020. More efforts from industrialized countries are expected for assisting and helping developing countries financially and technologically to reduce their GHG emission.

This article explores the factors that affect China's decision in legally binding GHG reduction commitments. As a developing country with the largest population in the world, clear barriers and limitations exist in China to reduce the GHG emissions. At the same time, China is making a great effort on mitigate climate change, establishing and reforming its energy and climate policies to achieve low-carbon development, and upgrading its economic and industrial structure to adopt the changing global situation. On the other hand, this paper has also studied the potential and possible solutions to cover the barriers in China, which also exist in most developing countries. In order to substantially mitigate global climate change, innovation is needed to create a more effective global cooperation and collaboration framework. To become a win-win strategy, this global cooperation and collaboration framework is the key factor that will help China to reduce its GHG emissions and contamination. Furthermore, it will also increase the sustainability of development in China and the world.

\section{References}

[1] UNFCCC. United Nations framework convention on climate change. New York: United Nations; 1992.

[2] UNFCCC. Kyoto Protocol to the United Nations framework convention on climate change. Bonn, Germany: Climate Change Secretariat; 1997.

[3] UNFCCC. Copenhagen Accord. Copenhagen; 2009.

4] UNFCCC. Launching of the Green Climate Fund. Durban; 2011.

[5] Connie Hedegaard, Kololec M. Statement at the opening of the high level segment of COP 17; 2011. http://unfccc.int/files/meetings/durban_nov_2011/ statements/application/pdf/111206_cop17_hls_european_union.pdf (last access: December 20, 2011).

[6] María del Mar Hidalgo García. Durban: Hacia la solución vinculante. Instituto Español de Estudios Estratégicos; 2012.

[7] EDITORIAL: Japan should not walk away from Kyoto Protocol. The Asahi Shimbun; 2011. http://ajw.asahi.com/article/views/editorial/Al201112130008 (last access: December 20, 2011)

[8] Bedritskiv A. Statement of the adviser to the president of the Russian Fed eration, Special Representative of the present of the Russian Federation of climate change; 2011. http:/unfccc.int/files/meetings/durban_nov_2011/ statements/application/pdf/111208_cop17_hls_russia.pdf (last access: December 20, 2011).

[9] Natarajan J. Statement at the high level segment of COP 17, India; 2011. http://unfccc.int/files/meetings/durban_nov_2011/statements/application/pdf/ 111207_cop17_hls_india.pdf (last access: December 20, 2011).

[10] Zhenhua X. Statement at the high level segment of COP 17, China: 2011 http://unfccc.int/files/meetings/durban_nov_2011/statements/application/pdf/ 111207_cop17_hls_china.pdf (last access: December 20, 2011).

[11] Yuan]. China propose 5 conditions in joining global climate framework regime after 2020; 2011. http://cdm.ccchina.gov.cn/web/NewsInfo.asp?NewsId=5734 (last access: December 20, 2011).

[12] Lewis B, Chestney N. Analysis: China climate role could be to corner U.S. Reuters; 2011. http://www.reuters.com/article/2011/11/16/us-un-climatechina-idUSTRE7AF1JU20111116 (last access: December 20, 2011).

[13] IEA. $\mathrm{CO}_{2}$ emissions from fuel combustion highlights. International Energy Agency: 2011.

[14] IEA. Integration of renewables status and challenges in China. International Energy Agency; 2011.

[15] Fu B, Zhuang X, Jiang G, Shi J, Lu Y. FEATURE: environmental problems and challenges in China. Environmental Science and Technology 2007:41(22):7597-602

[16] Andrews-Speed P. China's on-going energy efficiency drive: origins, progress and prospects. Energy Policy 2009;37:1331-44.

[17] Zhou N, Levine MD, Price L. Overview of current energy efficiency policies in China. Energy Policy 2010;38:6439-52.

[18] State Council. China's Agenda 21 - white paper on China's population, environment, and development in the 21st century. State Council; 1994.

[19] State Council. Program of action for sustainable development in China in the early 21st century. State Council; 2003.

[20] Price L, Levine MD, Zhou N, Fridley D, Aden N, Lu Hongyou, et al. Assessment of China's energy-saving and emission-reduction accomplishments and opportunities during the 11th Five Year Plan. Energy Policy 2011;39:2165-78.

[21] Liu L, Liu C, Sun Z. A survey of China's low-carbon application practice-opportunity goes with challenge. Renewable and Sustainable Energy Reviews 2011;15:2895-903.

[22] Yuan X, Zuo J. Transition to low carbon energy policies in China-from the FiveYear Plan perspective. Energy Policy 2011;39:3855-9.

[23] Ma HY, Oxley L, Gibson J. China's energy situation in the new millennium. Renewable and Sustainable Energy Reviews 2009;13:1781-99.

[24] Wang QYC. Barriers and opportunities of using the clean development mechanism to advance renewable energy development in China. Renewable and Sustainable Energy Reviews 2010;14:1989-98.

[25] Zhang $\mathrm{N}$, Lior $\mathrm{N}$, Jin $\mathrm{H}$. The energy situation and its sustainable development strategy in China. Energy 2011:36:3639-49.

[26] Zhong X, Can ZU. China afford to commit itself an emissions cap? An economic and political analysis. Energy Economics 2000;22:587-614.

[27] Tong Xiaobo. News: according to Jiankun He, low-carbon development is a great challenge and important task; 2010. http://energy.people.com.cn/GB/12139699.html (last access: December 20, 2011).

[28] Zhang Xiaohong, Han J, Zhao H, Deng S, Xiao H, Peng H, et al. Evaluating the interplays among economic growth and energy consumption and $\mathrm{CO}_{2}$ emission of China during 1990-2007. Renewable and Sustainable Energy Reviews 2012;16:65-72.

[29] Lin B, Yao X, Liu X. The strategic adjustment of China's energy use structure in the context of energy-saving and carbon emission-reducing initiatives. Social Science in China 2010;2010(1):59-72.

[30] Xue J.Annual report on China's low-carbon economic development 2011. Social Sciences Academic Press (China); 2011.

[31] Liu W, Lund H, Vad Mathiesen B, Zhang X. Potential of renewable energy systems in China. Applied Energy 2011;88:518-25.

[32] Cai W, Wang C, Wang $\mathrm{K}$, Zhang $\mathrm{Y}$, Chen J. Scenario analysis on $\mathrm{CO}_{2}$ emissions reduction potential in China's electricity sector. Energy Policy 2007;35:6445-56.

[33] Chien J, Noam L. Concentrating solar thermal power as a viable alternative in China's electricity supply. Energy Policy 2011;39:7622-36. 
[34] Cherni JA, Kentish J. Renewable energy policy and electricity market reforms in China. Energy Policy 2007;35:3616-29.

[35] Stavins RN. Experience with market-based environmental policy instruments. Handbook of environmental economics environmental degradation and institutional responses, vol. 1; 2003. p. 355-435 (Chapter 9)

[36] IEA. Reviewing existing and proposed emissions trading systems. International Energy Agency; 2010 .

[37] World Bank. State and trends of the carbon market. World Bank; 2011.

[38] Blyth W, Bunn D, Kettunen J, Wilson T. Policy interactions, risk and price formation in carbon markets. Energy Policy 2009;37:5192-207.

[39] Liu X. Extracting the resource rent from the CDM projects: Can the Chinese Government do better? Energy Policy 2010:38:1004-9.

[40] Yuan J, Kang J, Yu C, Hu Zhaoguang. Energy conservation and emissions reduction in China-progress and prospective. Renewable and Sustainable Energy Reviews 2011;15:4334-47.

[41] State Council. China's policies and actions for addressing climate change (2011). The State Council Information Office; 2011
[42] Bloomberg. Global renewable energy market outlook 2011. Bloomberg; 2011

[43] TRPC. CARBON 2011. Thomson Reuters Point Carbon; 2011.

[44] Grubb M. The economics of the Kyoto Protocol. World Economics 2003;4(3):143-89.

[45] Disch D, Rai K. Carbon finance: a guide for sustainable energy enterprises and NGOs. Global Village Energy Partnership; 2010.

[46] UNFCCC. Benefits of the clean development mechanism. UNFCCC; 2011.

[47] Han YXH. The Clean Development Mechanism and its implementation in China: an economic analysis. Energy Procedia 201 1;5:2278-82.

[48] Zhang Z. Toward an effective implementation of clean development mechanism projects in China. Energy Policy 2006:34:3691-701.

[49] Li J. Decarbonising power generation in China-Is the answer blowing in the wind? Renewable and Sustainable Energy Reviews 2010;14:1154-71.

[50] Karakosta C, Doukas H, Psarras ]. Technology transfer through climate change: setting a sustainable energy pattern. Renewable and Sustainable Energy Reviews 2010;14:1546-57. 